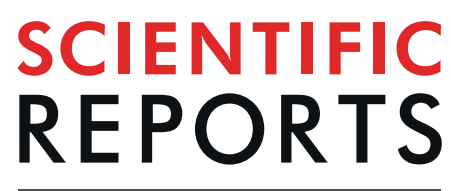

natureresearch

\title{
OPEN Near-future ocean warming and acidification alter foraging behaviour, locomotion, and metabolic rate in a keystone marine mollusc
}

\begin{abstract}
Rael Horwitz $\mathbb{1}^{1,2,12^{*}}$, Tommy Norin ${ }^{3,11,12}$, Sue-Ann Watson ${ }^{4}$, Jennifer C. A. Pistevos $\mathbb{1}^{1,2}$, Ricardo Beldade ${ }^{1,5}$, Simon Hacquart ${ }^{1}$, Jean-Pierre Gattuso ${ }^{6,7}$, Riccardo Rodolfo-Metalpa ${ }^{2,8}$, Jeremie Vidal-Dupiol ${ }^{2,9,10}$, Shaun S. Killen ${ }^{3}$ \& Suzanne C. Mills $\mathbb{D}^{1,2}$

Environmentally-induced changes in fitness are mediated by direct effects on physiology and behaviour, which are tightly linked. We investigated how predicted ocean warming (OW) and acidification (OA) affect key ecological behaviours (locomotion speed and foraging success) and metabolic rate of a keystone marine mollusc, the sea hare Stylocheilus striatus, a specialist grazer of the toxic cyanobacterium Lyngbya majuscula. We acclimated sea hares to $O \mathrm{~W}$ and/or $\mathrm{OA}$ across three developmental stages (metamorphic, juvenile, and adult) or as adults only, and compare these to sea hares maintained under current-day conditions. Generally, locomotion speed and time to locate food were reduced 1.5 - to 2 -fold when the stressors (OW or $O A$ ) were experienced in isolation, but reduced $\sim 3$-fold when combined. Decision-making was also severely altered, with correct foraging choice nearly $40 \%$ lower under combined stressors. Metabolic rate appeared to acclimate to the stressors in isolation, but was significantly elevated under combined stressors. Overall, sea hares that developed under OW and/or OA exhibited a less severe impact, indicating beneficial phenotypic plasticity. Reduced foraging success coupled with increased metabolic demands may impact fitness in this species and highlight potentially large ecological consequences under unabated $O W$ and $O A$, namely in regulating toxic cyanobacteria blooms on coral reefs.
\end{abstract}

Rising atmospheric carbon dioxide $\left(\mathrm{CO}_{2}\right)$ levels may lead to continued and accelerated global warming over the coming century ${ }^{1}$. The resulting elevated sea surface temperature (SST) (i.e. ocean warming; OW) is accompanied by increased partial pressure of $\mathrm{CO}_{2}\left(p \mathrm{CO}_{2}\right)$ in the ocean, thus rapidly changing the marine environment by increasing acidity (i.e. ocean acidification; OA) at unprecedented rates ${ }^{2}$. The Intergovernmental Panel on Climate Change (IPCC) has indicated that, by year 2100 , global mean SST will increase by $2-4{ }^{\circ} \mathrm{C}$ and seawater $\mathrm{pH}$ decrease by $0.14-0.43$ units $^{3}$, with concomitant effects on marine ecosystems. Marine invertebrates are critical

${ }^{1}$ PSL Université Paris: EPHE-UPVD-CNRS, USR 3278 CRIOBE, BP 1013, 98729, Papetoai, Moorea, French Polynesia. 2Laboratoire d'Excellence "CORAIL", Nouméa, Nouvelle-Calédonie, France. ${ }^{3}$ University of Glasgow, Institute of Biodiversity, Animal Health and Comparative Medicine, Graham Kerr Building, Glasgow, G12 80Q, United Kingdom. ${ }^{4}$ Australian Research Council Centre of Excellence for Coral Reef Studies, James Cook University, Townsville, Queensland, 4811, Australia. ${ }^{5}$ Pontificia Universidad Católica de Chile, Departamento de Ecología, Facultad de Ciencias Biológicas, Santiago, Chile. ${ }^{6}$ Sorbonne Université, CNRS, Laboratoire d'Océanographie de Villefranche, 181 chemin du Lazaret, F-06230, Villefranche-sur-mer, France. ${ }^{7}$ Institute for Sustainable Development and International Relations, Sciences Po, 27 rue Saint Guillaume, F-75007, Paris, France. ${ }^{8}$ ENTROPIE IRD - Université de La Réunion - CNRS, Nouméa, 98848, Nouvelle-Calédonie, France. ${ }^{9}$ IFREMER, UMR 241 EIO, BP 7004, 98719, Taravao, Tahiti, French Polynesia. ${ }^{10}$ IHPE, Université Montpellier, CNRS, IFREMER, Université Perpignan Via Domitia, F-34095, Montpellier, France. ${ }^{11}$ Present address: Technical University of Denmark, DTU Aqua: National Institute of Aquatic Resources, $2800 \mathrm{Kgs}$, Lyngby, Denmark. ${ }^{12}$ These authors contributed equally: Rael Horwitz and Tommy Norin. *email: horwitzrael@gmail.com 
for ecosystem functioning 4 . Thus, any effects of OW and OA in the coming decades on the behaviour and physiology of marine invertebrates, particularly molluscs (see refs. ${ }^{5,6}$ ), could substantially impact the biodiversity ${ }^{7}$ and functionality of marine communities and ecosystems, due to modifications in biotic interactions through changes in competition, predation, mutualism, or parasitism ${ }^{8}$, but few studies consider developmental acclimation of marine species to both OW and OA.

One way in which animals respond to a changing environment is through modifications to their behaviour ${ }^{9}$, and OW and OA affect a plethora of marine invertebrate behavioural traits ${ }^{10}$. Elevated $p \mathrm{CO}_{2}$ and/or temperature alter predator-prey behaviours in tropical ${ }^{11,12}$ and temperate ${ }^{13-15}$ gastropod and bivalve molluscs (e.g. ref. ${ }^{16}$ ); activity, defensive ${ }^{17}$, and predatory ${ }^{18}$ behaviour in cephalopod molluscs; and foraging behaviour (e.g. ref. ${ }^{19}$ ) and sound production ${ }^{20}$ in crustaceans.

Behavioural responses to a changing environment are also tightly linked with changes in physiology and organism metabolism ${ }^{21}$. Indeed, whole-animal metabolic rate is a key physiological trait with broad ecological relevance $^{22}$ that is linked with reproductive performance, survival, and fitness ${ }^{23}$. Among other biotic and abiotic factors, elevated temperature and/or $\mathrm{CO}_{2}$ are well known to affect growth and metabolic rates in many marine species $^{24-26}$

Evidence is emerging, however, that some species can adjust to changing ocean conditions over time through phenotypic plasticity, or acclimation ${ }^{27}$. Acclimation may involve phenotypically plastic responses in behaviour, physiology, or morphology, which can help maintain fitness in a new environment ${ }^{28,29}$. An organism might maintain a specific trait (e.g. growth rate) in a sub-optimal environment compared with present-day conditions because of plasticity in underlying metabolic processes supporting that trait ${ }^{30}$. Acclimation can occur via reversible phenotypic plasticity within a given life stage, via developmental plasticity with persistent changes on adult traits, as well as through transgenerational plasticity reflecting the environment experienced by an animal's predecessors $^{31}$. Whereas reversible acclimation occurs over relatively short periods of several days to months, often within a life stage ${ }^{32}$, developmental acclimation occurs when exposure of an organism to a specific environment in its early life stages permanently modifies behaviour or physiology that enhances its performance in that environment later in life ${ }^{33}$.

Few studies consider developmental acclimation of marine species to both $\mathrm{OW}$ and $\mathrm{OA}^{34}$. To date, most studies on environmental change have focused on a single life stage of marine species placed more or less directly into future scenarios (i.e. reversible acclimation) (but see review in ref. ${ }^{35}$ ). This "future shock" approach may shed light on species' stress tolerance, but the observed sensitivity to stressors may be inaccurate ${ }^{36}$. Apart from these short-term approaches, experiments should ideally include multiple stages in the life cycle of a species (i.e. developmental acclimation $)^{37}$, and even transgenerational acclimation ${ }^{35,38}$. As typical experimental setups are far from the slow progression of change in oceanic conditions, it is necessary to take these factors into account ${ }^{39,40}$. Whilst fish have been reported to show some developmental acclimation to warming and acidification ${ }^{41}$, no studies have investigated developmental acclimation responses to both these phenomena in molluscs.

Here, we investigate how projected near-future OW and OA affect locomotion and foraging behaviour, as well as metabolic rates, of a keystone marine mollusc, the circumtropical sea hare Stylocheilus striatus ${ }^{42}$ (Fig. 1). Specifically, we measure the behavioural and metabolic responses to a range of near-future warming and acidification conditions, both in isolation and in combination. We do this in adult sea hares that have been developmentally acclimated to four scenarios of OW and/or OA across three life stages (metamorphic, juvenile, and adult; see electronic supplementary material for an overview of $S$. striatus life stages) for a total of five weeks (developmental acclimation group), and we compare these to adult sea hares exposed to the same four scenarios of OW and/ or OA for two weeks during their adult life stage only (adult acclimation group; representing a "future shock" experimental approach) or maintained under current-day conditions throughout their lives (control group). $S$. striatus was chosen for this study because it plays an important role in benthic coral reef ecology, particularly as the predominant grazer of the toxic cyanobacterium Lyngbya majuscula ${ }^{43,44}$ that has detrimental effects on human health including skin, eye, and respiratory irritation ${ }^{45}$, prevents the settlement of coral larvae ${ }^{46}$, and can cause phase shifts from coral to algal dominated reefs ${ }^{47}$. S. striatus also has a short post-settlement stage ( 60 days) before reaching reproductive age and shows rapid growth (see Fig. S1 for duration times of the species' developmental life stages). The difference of three weeks between our 5-week developmentally acclimated and 2-week adult acclimated sea hares not only spans different and multiple life-stages, but also represents at least a third of the post-settlement stage of these animals.

\section{Results}

Behavioural responses. Time to foraging choice. Time to foraging choice of sea hares significantly increased with increasing severity of future climate change scenarios (Fig. 2a, Supplementary Table S3). For developmentally acclimated sea hares, the amount of time to reach and choose between the stimulus and control chambers increased from $2.22 \pm 0.23 \mathrm{~min}$ for control animals to $3.69 \pm 0.20 \mathrm{~min}$ in the low pH treatment $\left(\mathrm{pH}_{\mathrm{NBS}} 7.85\right.$ and $\left.28^{\circ} \mathrm{C}\right)$ and finally to $8.49 \pm 0.38 \mathrm{~min}$ for sea hares in the extreme $\mathrm{pH}$ treatment $\left(\mathrm{pH}_{\mathrm{NBS}} 7.65\right.$ and $\left.28^{\circ} \mathrm{C}\right)$, showing a significant difference between all treatments $(p<0.0001$ for all contrasts; Supplementary Table S3; Fig. 2a). The same pattern was observed for adult acclimated sea hares $(p<0.0001$ for all contrasts; Supplementary Table S3; Fig. 2a).

Sea hares in the elevated temperature treatments took on average 2 mins longer to reach and choose between the stimulus and control chambers compared to sea hares in the control temperature, regardless of pH (Fig. 2a). The same pattern was observed for both acclimation groups, but adult acclimated sea hares always took on average 1 min longer to reach and choose between the choice chambers.

Comparison between the two acclimation groups showed that Time to foraging choice was significantly reduced for sea hares having undergone developmental acclimation compared to those that were only acclimated 

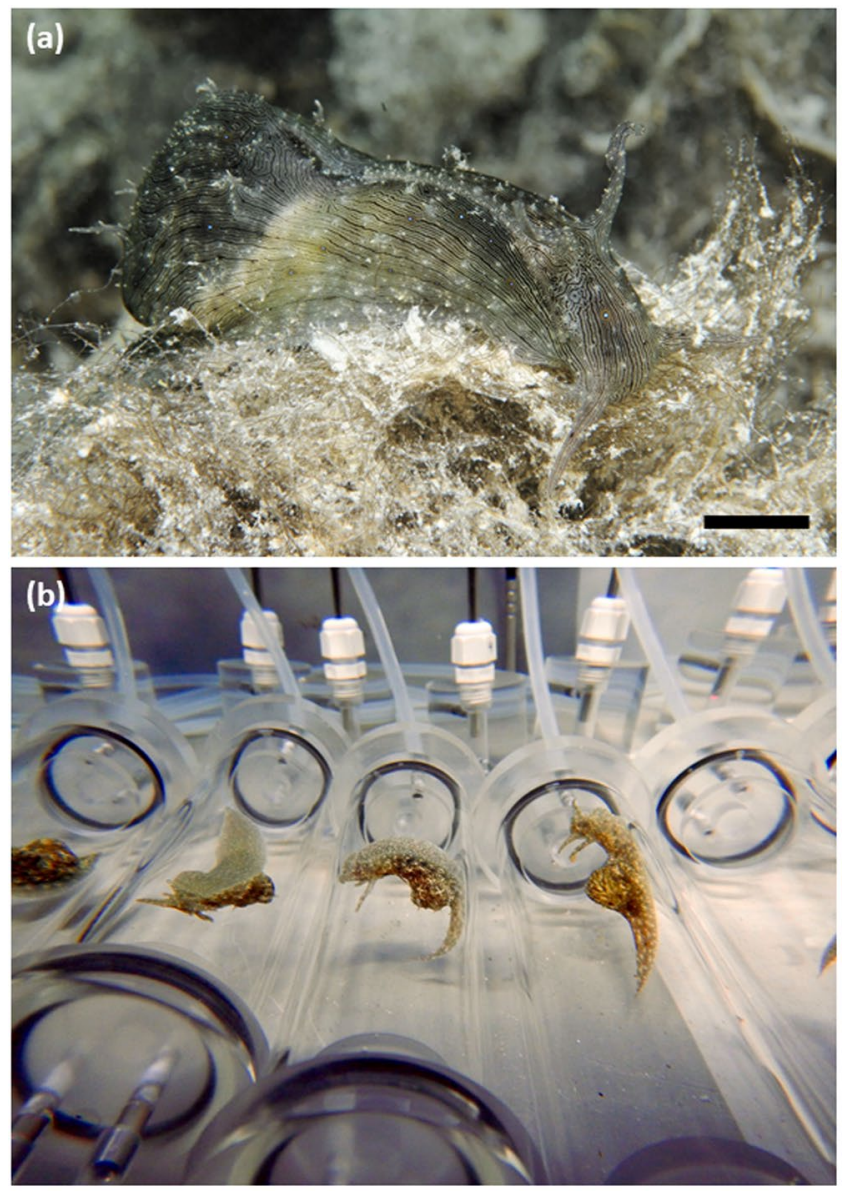

Figure 1. The circumtropical sea hare Stylocheilus striatus. (a) Photo of S. striatus foraging on the cyanobacteria Lyngbya majuscula. Photograph by Frederic Zuberer. Scale bar $=10 \mathrm{~mm}$. (b) Photo of S. striatus in respirometry chambers. The optical oxygen probes placed in an external recirculation loop can be seen in the background.

as adults $(p<0.0001)$, with the exception of animals subjected to the low $\mathrm{pH}$ treatment $\left(\mathrm{pH}_{\mathrm{NBS}} 7.85\right.$ and $\left.28^{\circ} \mathrm{C}\right)$ $(p=0.52$, Supplementary Table S5).

Correct foraging choice. Sea hares from all groups and treatments, except those that were developmentally acclimated in the extreme $\mathrm{pH}$ treatment $\left(\mathrm{pH}_{\mathrm{NBS}} 7.65\right.$ and $\left.28^{\circ} \mathrm{C}\right)(p=0.715)$, made an active choice between the stimulus and control cue chambers (all $p$-values $<0.5$; Supplementary Table S3). Furthermore, there was high repeatability of foraging choices between the two trials with the same animals $(R=0.711, p<0.0001)$, indicating individual sea hare consistency in foraging choice, regardless of outcome (correct or not).

All sea hares in the control treatment chose the chambers with water that had been conditioned with cyanobacteria, i.e. in terms of foraging, $100 \%$ made the correct foraging choice (Fig. $2 \mathrm{~b}$ ). However, sea hares made more foraging choice errors as the severity of climate change conditions increased (Fig. 2b). For sea hares that experienced developmental acclimation, the percentage of correct choices was significantly lower in the combined $\left(\mathrm{pH}_{\mathrm{NBS}} 7.85\right.$ and $\left.31^{\circ} \mathrm{C}\right)$, elevated temperature $\left(\mathrm{pH}_{\mathrm{NBS}} 8.1\right.$ and $\left.31^{\circ} \mathrm{C}\right)$, and extreme $\mathrm{pH}\left(\mathrm{pH}_{\mathrm{NBS}} 7.65\right.$ and $\left.28^{\circ} \mathrm{C}\right)$ treatments when compared to control animals $(p=0.0094, p=0.0487$ and $p=0.0012$, respectively). However, there were no significant differences when comparing the low $\mathrm{pH}\left(\mathrm{pH}_{\mathrm{NBS}} 7.85\right.$ and $\left.28^{\circ} \mathrm{C}\right)$ treatment with the control (see Fig. 2b). Similarly, the corresponding sea hares in the adult acclimated group also showed significantly lower foraging choice accuracy in the combined $\left(\mathrm{pH}_{\mathrm{NBS}} 7.85\right.$ and $\left.31^{\circ} \mathrm{C}\right)$, elevated temperature $\left(\mathrm{pH}_{\mathrm{NBS}} 8.1\right.$ and $\left.31^{\circ} \mathrm{C}\right)$ and extreme $\mathrm{pH}\left(\mathrm{pH}_{\mathrm{NBS}} 7.65\right.$ and $\left.28^{\circ} \mathrm{C}\right)$ treatments when compared to the control $(p=0.0079, p=0.0255$ and $p=0.0007$, respectively), but not in the low $\mathrm{pH}\left(\mathrm{pH}_{\mathrm{NBS}} 7.85\right.$ and $\left.28^{\circ} \mathrm{C}\right)$ treatment (Fig. $2 \mathrm{~b}$; Supplementary Table S3).

Sea hares in the elevated temperature treatments (Fig. 2b) made on average $25 \%$ more foraging choice errors compared to sea hares in control temperatures, regardless of ocean acidification treatment (Fig. $2 \mathrm{~b}$ ). The same pattern was observed for both acclimation groups, with no statistically significant difference among developmentally and adult acclimated animals ( $p>0.05$ for all treatments, Supplementary Table S5).

Locomotion speed. Locomotion speed of control animals was $9.69 \pm 1.46 \mathrm{~cm} \mathrm{~min}^{-1}$ (Fig. 2c). However, for developmentally acclimated animals, speed decreased with increasing severity of future climate change scenarios down to $2.69 \pm 0.17 \mathrm{~cm} \mathrm{~min}^{-1}$ for sea hares from the extreme $\mathrm{pH}$ treatment $\left(\mathrm{pH}_{\mathrm{NBS}} 7.65\right.$ and $\left.28^{\circ} \mathrm{C}\right)(p<0.0001$ for all 
(a)

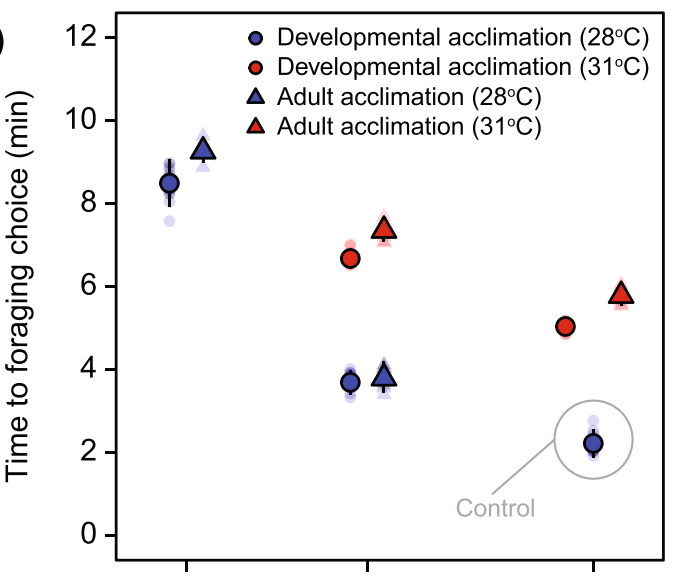

(b)

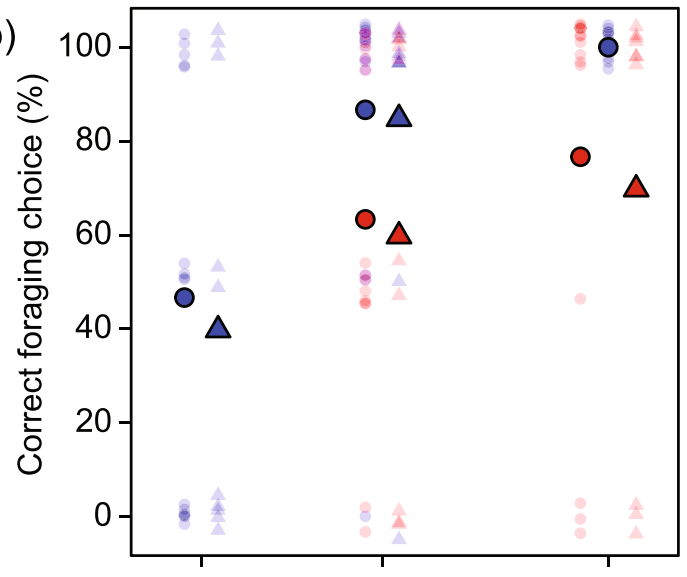

(c)

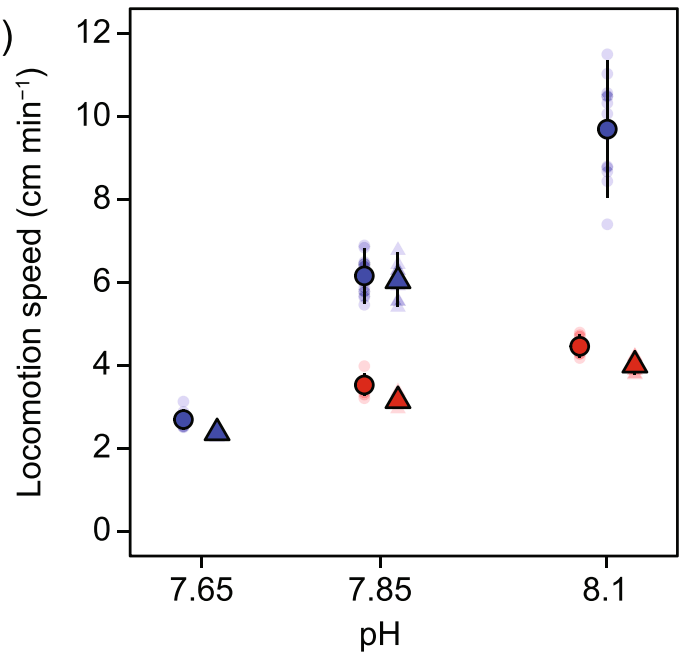

Figure 2. Behavioral responses of the developmental and adult acclimation groups of Stylocheilus striatus in T-maze trials. Mean and individual T-maze results showing (a) Time to foraging choice, (b) Correct foraging choice and (c) Locomotion speed of $S$. striatus from the developmental (circles; $n=15$ ) and adult (triangles; $n=10$ ) acclimation groups in each of the five treatments. Large symbols (circles or triangles) with black outlines are means \pm SD and smaller, semi-transparent symbols are the mean of the two repeated measurements for each individual sea hare. Data points for the developmental and adult acclimation groups have been offset an even amount around each of their respective $\mathrm{pH}$ values (i.e. along the $\mathrm{x}$-axis) to avoid overlap. Moreover, in panel (b), the data points for individual sea hares have values of $0 \%$ (incorrect choice in both technical repeats), $50 \%$ (one correct and one incorrect choice), or $100 \%$ (correct choice in both technical repeats) but have been offset along the y-axis for visual clarity.

contrasts; Fig. 2c; Supplementary Table S3). Similar results were found for adult acclimated sea hares, with speed decreasing from $6.06 \pm 0.74$ to $2.39 \pm 0.07 \mathrm{~cm} \mathrm{~min}^{-1}$ from the low $\mathrm{pH}$ treatment $\left(\mathrm{pH}_{\mathrm{NBS}} 7.85\right.$ and $\left.28^{\circ} \mathrm{C}\right)$ to the extreme $\mathrm{pH}$ treatment $\left(\mathrm{pH}_{\mathrm{NBS}} 7.65\right.$ and $\left.28^{\circ} \mathrm{C}\right)$, respectively $(p<0.0001$ for all contrasts; Fig. $2 \mathrm{c}$; Supplementary Table S3). 


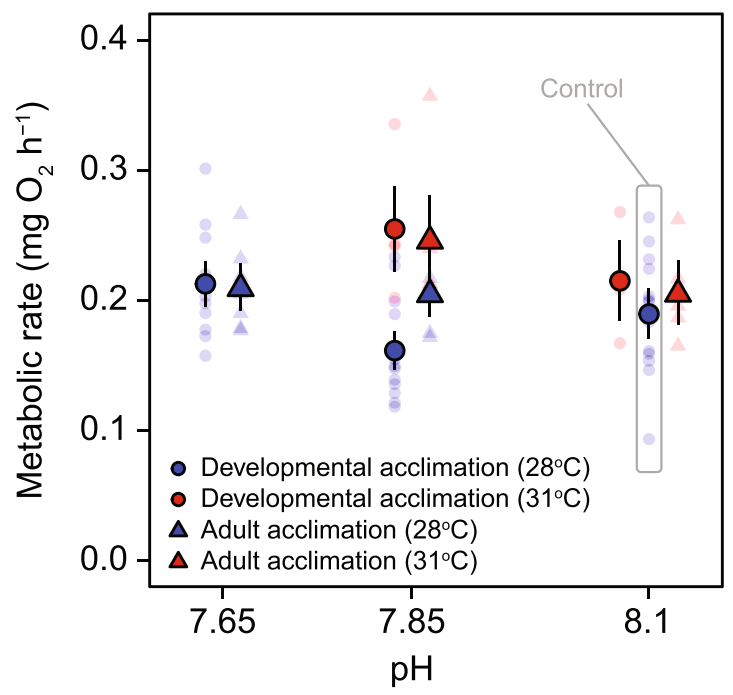

Figure 3. Body-mass-adjusted metabolic rate (oxygen consumption rate, $\dot{M}_{\mathrm{O}_{2}}$ ) of the developmental and adult acclimation groups of Stylocheilus striatus. Large symbols (circles or triangles) with black outlines are means \pm SD and smaller, semi-transparent symbols are values for individual sea hares. Sample sizes for each treatment are given in the main text. As for Fig. 2, data points for the developmental and adult acclimation groups have been offset an even amount around each of their respective $\mathrm{pH}$ values (i.e. along the $\mathrm{x}$-axis) to avoid overlap.

Sea hares in the elevated temperature treatment $\left(\mathrm{pH}_{\mathrm{NBS}} 8.1\right.$ and $\left.31^{\circ} \mathrm{C}\right)$ moved $6 \mathrm{~cm} \mathrm{~min}^{-1}$ slower compared to the control $\left(\mathrm{pH}_{\mathrm{NBS}} 8.1\right.$ and $\left.28^{\circ} \mathrm{C} ; p<0.0001\right)$, but only $2.5 \mathrm{~cm} \mathrm{~min}^{-1}$ slower compared to animals in control temperature and low $\mathrm{pH}$ (i.e. $\mathrm{pH}_{\mathrm{NBS}} 7.85$ and $28^{\circ} \mathrm{C} ; p<0.0001$ ).

There were no significant differences in locomotion speed among developmentally and adult acclimated sea hares within the same OW and/or OA treatments (Fig. 2c; $p=0.102-0.981$; Supplementary Table S5).

Metabolic rate. The $\dot{M}_{\mathrm{O}_{2}}$ of sea hares from reduced $\mathrm{pH}$ alone or elevated temperature alone scenarios were similar to those of control animals, at $\sim 0.2 \mathrm{mg} \mathrm{O}_{2} \mathrm{~h}^{-1}$ (Fig. 3; Supplementary Table S3). However, the combined effect of low $\mathrm{pH}$ and elevated temperature $\left(\mathrm{pH}_{\mathrm{NBS}} 7.85\right.$ and $\left.31^{\circ} \mathrm{C}\right)$ significantly elevated $\dot{M}_{\mathrm{O}_{2}}$ of both developmentally acclimated $(p=0.0051)$ and adult acclimated $(p=0.0061)$ sea hares when compared to control animals, i.e. the combination of $\mathrm{pH}$ and temperature predicted for the year 2100 had a synergistic effect on sea hare $\dot{M}_{\mathrm{O}_{2}}$ that was not observable for either stressor alone (Fig. 3). There were no significant differences in the $\dot{M}_{\mathrm{O}_{2}}$ of sea hares between either the elevated temperature $\left(\mathrm{pH}_{\mathrm{NBS}} 8.1\right.$ and $\left.31^{\circ} \mathrm{C}\right)$ or the extreme $\mathrm{pH}\left(\mathrm{pH}_{\mathrm{NBS}} 7.65\right.$ and $\left.28^{\circ} \mathrm{C}\right)$ treatments and the control for both developmentally and adult acclimated animals (Fig. 3; Supplementary Table S3), with the caveat that sample sizes were low for the elevated temperature groups $(n=4$ for developmental acclimation and $n=5$ for adult acclimation). Curiously, the treatment with low $\mathrm{pH}$ alone $\left(\mathrm{pH}_{\mathrm{NBS}} 7.85\right.$ and $\left.28^{\circ} \mathrm{C}\right)$ tended to reduce the $\dot{M}_{O}$ of developmentally acclimated animals in comparison with the control, albeit this was not significant $(p=0.0624)$.

Nonetheless, the $\dot{M}_{\mathrm{O}_{2}}$ from this low $\mathrm{pH}$ treatment $\left(\mathrm{pH}_{\mathrm{NBS}} 7.85\right.$ and $28^{\circ} \mathrm{C}$ ) was significantly lower for developmentally compared to adult acclimated sea hares, while all other within-treatment comparisons between developmentally and adult acclimated groups showed no significant differences in $\dot{M}_{\mathrm{O}_{2}}(p>0.05$; Supplementary Table S5; Fig. 3).

\section{Discussion}

Our results show that behavioural traits linked to foraging and metabolic rates of a keystone marine mollusc are affected by exposure to future SST conditions ${ }^{1}$. Elevated $\mathrm{CO}_{2}(\mathrm{OA})$ and elevated temperature $(\mathrm{OW})$ alone or in combination caused behavioural modifications, including increased time to foraging, incorrect foraging choices, and reduced locomotor speed. However, certain behavioural modifications were less severe for developmentally compared to adult acclimated sea hares, suggesting a potential for adaptive developmental plasticity to future climate change conditions that is not observed in animals subjected to short-term changes in their environment as adults. Furthermore, the metabolic rate of sea hares from both acclimation groups remained relatively unchanged to elevated $\mathrm{CO}_{2}$ or temperature alone, either due to a lack of physiological response or possible acclimation through plasticity, but in both cases the responses were similar during development as during adulthood. However, no acclimation in metabolic rate was found in both developmentally and adult acclimated sea hares when OA and OW were combined. Such increased metabolic rates, which are not compensated for with elevated foraging, place this opisthobranch mollusc at risk under future climate change conditions. As Stylocheilus striatus is the principal herbivore of toxic cyanobacteria in a trophic cascade on coral refs. ${ }^{43}$, these effects can have considerable implications for ecosystem functioning, structure, and potentially human health.

Our results indicate that end-of-the-century projections of $p \mathrm{CO}_{2}$ and temperature may impair foraging by this important marine mollusc, decreasing locomotion speed and increasing time to foraging choice. Similar findings 
were described in the marine gastropod Concholepas concholepas, with increased $p \mathrm{CO}_{2}$ negatively affecting locomotor and sensory performance, thereby decreasing their foraging ability ${ }^{48}$. Generally speaking, high $p \mathrm{CO}_{2}$ levels appear to slow down the sea hares in our study, possibly due to the additive negative effects on cognitive, sensory (i.e. olfactory), and locomotor performance found in other organisms ${ }^{49}$. The combination of elevated temperature and elevated $p \mathrm{CO}_{2}$ has a synergistic detrimental effect on movement, as well as on decision making and time to foraging choice (Fig. 2), while increasing metabolic rate (Fig. 3). An increase in metabolic rates under combined elevated temperature and $p \mathrm{CO}_{2}$ conditions $s^{50}$, while overall foraging success declines, points towards energetic trade-offs (i.e. higher costs for the maintenance of cellular homeostasis and biochemical processes; ref. ${ }^{51}$ ). It is possible that sea hares may move less due to a decreased energy surplus for movement and/or its altered cognitive and olfactory faculties to locate its food source. Additional work could determine the optimal movement speed of the sea hares (i.e. the speed at which they minimise their cost of transport) to evaluate the exact energetic trade-offs between movement costs and maintenance metabolism. Collectively, for all of the behaviours tested here, we found a greater effect under combined stressors as compared to individual stressors alone (Fig. 2). This is in line with previous works on the effect of multiple stressors on the behaviour of molluscs ${ }^{48}$ and fish ${ }^{52}$.

In addition to increasing foraging time, elevated $p \mathrm{CO}_{2}$ levels and/or temperature conditions also compromised decision-making when attempting to find food. The percentage of correct choices made by sea hares at elevated $p \mathrm{CO}_{2}$ levels and/or temperature conditions was 36 and $40 \%$ lower in the developmentally and adult acclimated groups, respectively, compared to the control (Fig. 2b). Decision-making was most disrupted in sea hares reared in extreme $\mathrm{pH}$ conditions (with correct choice being 53 and 55\% lower, respectively compared to control animals). This behavioural effect may be related to a reduction in chemosensory ability, as reported in previous studies where elevated $p \mathrm{CO}_{2}$ levels was found to interfere with neurotransmitter receptor function, potentially $\mathrm{GABA}_{\mathrm{A}}$-like receptors, thus compromising behaviour of snails ${ }^{11,53}$ and marine fishes ${ }^{54}$. Furthermore, in gastropods, a wide range of behaviours, including foraging, are mediated by chemical compounds known as secondary metabolites, and S. striatus are known to use the secondary metabolites produced by Lyngbya majuscula in foraging ${ }^{55}$. As such, disruption to decision-making may have arisen either from the compromised detection of stimulus cues (i.e. the perception of chemical cues ${ }^{54,56}$ ) or from an alteration of the chemical cues themselves ${ }^{57}$. Regardless of the mechanism, our results suggest that OA and OW disrupt the ability of this mollusc to identify its food source, thus potentially reducing food consumption.

Elevated $p \mathrm{CO}_{2}$, according to OA scenarios for the year 2100 and beyond, had no significant impact on metabolic rate of $S$. striatus at ambient temperature $\left(28^{\circ} \mathrm{C}\right)$. Similar results were found for another mollusc, the tropical humpbacked conch (Gibberulus gibberulus gibbosus ${ }^{58}$, where there was no effect of elevated $p \mathrm{CO}_{2}$ on respiratory performance at any of the tested temperatures (range $28-33^{\circ} \mathrm{C}$ ) (also see ref. ${ }^{11}$ ). On the other hand, elevated temperature resulted in a slight increase in metabolic rate of sea hares from both acclimation groups in the present study, however these were not significant. A similar case was found in another mollusc from the same region, the pearl oyster Pinctada margaritifera, where oxygen consumption was maximised at $30^{\circ} \mathrm{C}$ but fell dramatically at $34^{\circ} \mathrm{C}^{24}$. An increase in environmental temperature typically results in elevated metabolic rate in ectotherms, reflecting rate-enhancing effects of temperature on biochemical reaction ${ }^{59}$. However, temperature-dependence of metabolism is subject to acclimatory or evolutionary changes and thus also depends on the physiological state of the animals, as well as their environmental conditions and history of thermal adaptation or acclimation ${ }^{59-61}$. In the present study, a $3^{\circ} \mathrm{C}$ increase in temperature (from 28 to $31^{\circ} \mathrm{C}$ ) under the current ambient $\mathrm{CO}_{2}$ conditions had no significant effect on the metabolic rate for either developmentally or adult acclimated $S$. striatus. This may reflect metabolic adaptation to a fluctuating temperature regime in intertidal and shallow water habitats as previously found in other molluscs ${ }^{62}$, and similar fluctuating conditions are found in Moorea (temperatures recorded from 2007-2016: $\min =25.1^{\circ} \mathrm{C}$ in October 2015; $\max =30.8^{\circ} \mathrm{C}$ in April 2016; see ref. ${ }^{63}$ ).

The metabolic rate of sea hares exposed to $\mathrm{OW}$ and $\mathrm{OA}$ in combination was significantly higher than that of the control animals for both developmentally and adult acclimated animals, indicating that hypercapnia resulted in an elevated energy demand when combined with temperature stress. It is unlikely that the elevated metabolic rates were due to greater sea hare movement in the respirometry chambers, as sea hares showed reduced locomotion in T-maze trials with increasing severity of future climate change scenarios. Instead, evidence that the combination of OW and OA leads to elevated metabolic costs have also been shown in crustaceans ${ }^{50}$ and bivalves ${ }^{64}$, and is likely due to elevated physiological costs of the two stressors combined ${ }^{65}$. Importantly, if the energy demand of the sea hares is increasing while their foraging ability is decreasing, this may threaten future population sustainability and, consequently, ecosystem function.

Developmental plasticity is widespread among animals ${ }^{66}$, and several studies have demonstrated the importance of exposure to elevated temperature and/or $p \mathrm{CO}_{2}$ during early-life stages for the performance of adults ${ }^{33,41}$. Interestingly, in our study, when the behavioural and metabolic traits were compared between the developmentally and adult acclimated sea hares, both groups exhibited similar responses under OW and OA in almost all cases. However, the time taken to make a decision when identifying their food source was significantly shorter for developmentally acclimated individuals in all treatments, except for the low $\mathrm{pH}$ treatment (i.e. $\mathrm{pH}_{\mathrm{NBS}} 7.85$ and $28^{\circ} \mathrm{C}$; cf. Fig. 2a). Similar results were observed for correct foraging choice, although these were not significantly different (Fig. 2b). These results highlight the need to avoid "future shock" approaches in studies on climate change stressors that likely overestimate the sensitivity of species to stressors ${ }^{36,67}$. Even though this phenotypically plastic response during development may help S. striatus cope with foraging in future warmer and more acidic oceans, the negative effects of elevated $p \mathrm{CO}_{2}$ and/or temperature on the majority of the traits measured in this study were not alleviated following developmental acclimation. Emerging evidence demonstrates how plasticity of individuals can also depend on the environmental conditions experienced by previous generations ${ }^{40}$. When individuals are exposed to $\mathrm{OW}$ and/or OA, transgenerational acclimation has been reported to have positive effects on the performance of their offspring that experience the same conditions (e.g. refs. ${ }^{35,68}$ ). Although such 
studies are laborious, future work on S. striatus should incorporate this aspect of acclimation if we are to truly understand the scope for phenotypic plasticity to assist this species to persist in the face of environmental change.

Overall, our findings indicate that elevated temperature and $p \mathrm{CO}_{2}$ conditions predicted for the future could reduce $S$. striatus foraging success by: (1) decreasing locomotion speed and movement, consequently increasing the amount of time taken to locate their food; (2) reducing the ability to detect a food source; (3) impairing decision-making; or (4) a combination of the modified foraging behaviours mentioned above. S. striatus is the primary herbivore in a coral reef trophic cascade, of which the cyanobacterium $L$. majuscula is the primary producer $^{44}$. L. majuscula is known to harbour a potentially toxinogenic complex and produces more than 70 bioactive compounds, of which some are highly toxic ${ }^{69}$, causing multiple problems for humans including dermatosis, chelonitoxism, and food poisoning via the consumption of "infected" fish and turtles" . Furthermore, the cyanobacterium prevents the settlement of coral larvae ${ }^{41}$ and can cause phase shifts from coral to algal dominated refs. ${ }^{47}$, hence any changes in the foraging behaviour of S. striatus, the principal herbivore in this trophic web, may have cascading impacts on the ecosystem. Combinations of behavioural abnormalities in keystone species such as this are likely to alter complex trophic interactions in marine food webs, which often involve multiple species and indirect effects ${ }^{12,13,70}$. Behavioural alterations, including modified foraging ensuing elevated $p \mathrm{CO}_{2}$ and temperature levels caused by global change, are likely to alter the fragile equilibrium of this food web structure with consequences that are difficult to predict.

The significant changes demonstrated here in behavioural and physiological traits of this marine mollusc under predicted near-future OW and OA may have significant ecological ramifications. As metabolic rates increase under warming and acidifying conditions (Fig. 3), sea hares may need to consume food of higher energetic/nutritional value or, alternatively, forage more in order to maintain their performance as environmental conditions change ${ }^{65}$. However, with impaired foraging skills as observed here, sea hares may be at risk. Individual performance may be directly affected via a shift in the balance of energy intake (reduced from lower foraging success) $v s$. expenditure (from higher metabolic rate), potentially impacting optimal foraging strategies ${ }^{71}$. Since $S$. striatus rely heavily on sensory functions for their survival and growth, compromised chemosensory function as a result of elevated $p \mathrm{CO}_{2}$ and temperature may affect the species significantly. One possible outcome may be a shift in species dominance from 'sensory specialists' (e.g. S. striatus) to more 'sensory generalists', which generally possess highly plastic behaviours and include detrimental invasive species ${ }^{72}$. Furthermore, elevated $p \mathrm{CO}_{2}$ and/or temperature may alter trophic interactions by reducing cyanobacterial palatability (as observed for macroalgae ${ }^{73}$ and seagrass ${ }^{74}$ ) and, consequently, cyanobacteria removal by S. striatus (via a reduction in foraging), although this needs to be tested.

Ultimately, a reduction in foraging as a result of impaired food cue detection under climate change, along with a potential reduction in food palatability, may affect the important role of sea hares for regulating toxic blooms of cyanobacteria on tropical coral reefs.

\section{Methods}

Sample collection and experimental treatment groups. In November 2016, 360 specimens of metamorphic Stylocheilus striatus ( $3 \mathrm{~mm}$ in length; see electronic supplementary material for an overview of $S$. striatus life stages) were collected from Moorea lagoon (French Polynesia; $149^{\circ} 50^{\prime} \mathrm{W}, 17^{\circ} 30^{\prime} \mathrm{S}$ ), at $1-2 \mathrm{~m}$ depths on sand flats within blooms of the cyanobacteria Lyngbya majuscula (Fig. 1a). Thirty sea hares were randomly assigned to each of twelve aquaria $(40 \mathrm{~L})$ at the CRIOBE research station, supplied with aerated running seawater $\left(0.5 \mathrm{~L} \mathrm{~min}^{-1}\right)$ at ambient $\mathrm{pH}$ and temperature (see electronic supplementary material for details on the flowthrough seawater system) and were fed every two days with L. majuscula [3 $\mathrm{g}$ (wet weight) per sea hare] for the entire duration of the experiment.

After an initial laboratory habituation period ( $3 \mathrm{~d}$ ) (Fig. S1), the temperature and/or $\mathrm{pH}$ of the seawater supplying the twelve aquaria were gradually changed $\left(+1^{\circ} \mathrm{C}\right.$ day $^{-1}$ and/or $-0.1 \mathrm{pH}$ unit day ${ }^{-1}$, respectively) over three days to obtain the five different treatment groups: (i) control (present-day pH and temperature; $\mathrm{pH}_{\mathrm{NBS}}$ range $8.10-8.15$ and $\left.28^{\circ} \mathrm{C}\right)$; (ii) low $\mathrm{pH}\left(\mathrm{pH}_{\mathrm{NBS}}\right.$ target value 7.85 and $\left.28^{\circ} \mathrm{C}\right)$; (iii) elevated temperature $\left(\mathrm{pH}_{\mathrm{NBS}}\right.$ range 8.10-8.15 and $31^{\circ} \mathrm{C}$ ); (iv) low $\mathrm{pH}$ and elevated temperature $\left(\mathrm{pH}_{\mathrm{NBS}}\right.$ target value 7.85 and $31^{\circ} \mathrm{C}$ ); and (v) extreme $\mathrm{pH}\left(\mathrm{pH}_{\mathrm{NBS}}\right.$ target value 7.65 and $\left.28^{\circ} \mathrm{C}\right)$. Out of the twelve aquaria, both the control $\left(\mathrm{pH}_{\mathrm{NBS}} 8.10-8.15\right.$ and $\left.28^{\circ} \mathrm{C}\right)$ and low $\mathrm{pH}\left(\mathrm{pH}_{\mathrm{NBS}} 7.85\right.$ and $\left.28^{\circ} \mathrm{C}\right)$ treatments had three replicate aquaria, whereas the remainder of the treatments only had two replicate aquaria each due to laboratory space constraints. Low $\mathrm{pH}$ and elevated temperature were in accordance with the IPCC "business-as-usual" scenario (RCP 8.5) for 2100". The pH of 7.65 was included as a more extreme OA scenario. Temperature, salinity, and carbonate chemistry data from experimental aquaria are summarised in Supplementary Table S1.

The sea hares were initially maintained in each of their respective treatments for three weeks, during which time they first transitioned from metamorphic into juveniles and finally into their adult stage (Fig. S1). After these first three weeks (i.e. upon reaching adulthood), 60 sea hares were randomly selected from the control treatment (thus leaving 30 control animals) and gradually acclimated (at the rates described above and in four temporary acclimation aquaria) in parallel with the developmentally acclimated animals to each of the four treatment conditions with modified temperature and/or $\mathrm{pH}$ to serve as the adult acclimation group (representing a "future shock" experimental approach). After reaching their target acclimation conditions ( $3 \mathrm{~d})$, the 60 adult acclimated animals were removed from their temporary acclimation aquaria and placed in several labelled plastic tubs (fish breeding boxes; $20 \times 10 \times 10 \mathrm{~cm}$ ) with large mesh panels to allow water circulation, which were floating in the replicate aquaria of the four treatment conditions with modified temperature and/or $\mathrm{pH}$. All developmentally acclimated animals, including the remaining controls, were handled similarly; i.e. transferred from the main aquaria and placed in labelled plastic tubs of the same type floating in their aquaria. All animals were then kept in their respective seawater treatment for another two weeks (see Fig. S1 for experimental timeline), meaning that the developmentally acclimated animals experienced a total of five weeks acclimation, while the adult acclimated 
animals were only acclimated for two weeks. A period of two weeks was chosen to correspond to the average exposure time used in the majority of "future shock" experimental studies ${ }^{67}$.

Carbonate chemistry. Temperature, $\mathrm{pH}_{\mathrm{NBS}}$, and salinity in the aquaria were measured daily (YSI Professional Plus, Handheld Multiparameter Instrument) (Supplementary Table S1). Total alkalinity (TA) of seawater in the aquaria and mixing tanks was estimated by Gran titration (888 Titrando, Metrohm, Switzerland) from water samples taken weekly from each of the treatment tanks. All measurements and calculations are summarised in the electronic Supplementary Material Table S1.

Behavioural responses. Behavioural experiments were performed in a T-maze setup to evaluate the locomotor speed and foraging responses of $S$. striatus to water-borne food stimuli (cyanobacteria in seawater) under each of the five treatments conditions (see electronic Supplementary Material Fig. S2 for details on the T-maze setup). At the start of each trial, each sea hare was habituated for $5 \mathrm{~min}$ by placing it at the base of the T-maze starting lane behind a grid preventing access to the rest of the lane. At the start of each trial, the grid was removed and we subsequently recorded (i) 'Time to foraging choice' ( $\mathrm{min}$ ), the time it took the sea hare to reach the end of the $15 \mathrm{~cm}$ long starting lane and first enter one of the T-maze arms (i.e. one of the choice chambers); (ii) 'Correct foraging choice' (Yes or No), whether the sea hare entered the choice chamber receiving seawater conditioned with L. majuscula or not; and (iii) 'Locomotion speed' $\left(\mathrm{cm} \mathrm{min}{ }^{-1}\right)$, the time it took the sea hare to first reach a choice chamber regardless of which one it was.

Each trial lasted a maximum of $10 \mathrm{~min}$, within which time all sea hares had made a choice between the stimulus or control cue chambers. The sea hare was then removed, water drained from the set-up, and the T-maze cleaned to avoid mucus trail following ${ }^{48}$. The T-maze setup was then refilled with water, but with the water sources switched between the arms, and the same sea hare was tested again in order to confirm that no directional bias could have affected the animals' behaviour. Experiments were run for individual sea hares from both the developmentally and adult acclimated groups and at seawater $\mathrm{pH}$ and temperatures representative of their respective treatments.

Metabolic rate. Metabolic rates of sea hares under each of the five treatments for both developmentally and adult acclimated groups were estimated from rates of oxygen uptake $\left(\dot{M}_{O_{2}}\right)$ using intermittent-closed respirometry [cf. ref. ${ }^{75}$ ] (Fig. 1b, see electronic supplementary material for details). Respirometry experiments were performed in parallel with the behavioural trials and therefore on separate individuals. Unforeseen electrical problems resulted in sample sizes between 4-14 and 5-7 individuals per treatment for the developmentally and adult acclimated groups, respectively (Supplementary Table S2).

Sea hares were introduced into the respirometry chambers a few minutes before the first automated $\dot{M}_{\mathrm{O}_{2}}$ recordings were started in the afternoon and remained there for 14.5-16.7 h until the following morning, which produced between 72 and $83 \dot{M}_{O_{2}}$ recordings per treatment. Prior to transferring sea hares to the respirometry setup, food had been withheld for $\sim 20 \mathrm{~h}$ to ensure the sea hares were post-absorptive for the metabolic rate measurements. Upon completion of metabolic rate measurements in the morning, the sea hares were removed from their respirometry chambers, gently blotted dry, and weighed to the nearest mg (wet weight), and returned to their aquaria at their respective temperature and/or $\mathrm{pH}$ treatment.

Data analysis and statistics. All statistical analyses were performed in $\mathrm{R}^{76}$. Differences between treatment groups in Time to foraging choice, Locomotion speed, and $\dot{M}_{\mathrm{O}_{2}}$ were evaluated from linear mixed-effects (LME) models using the $l m e 4$ package ${ }^{77}$, while differences between treatment groups in Correct foraging choice was evaluated from a generalised linear mixed-effects (GLME) model, also using lme4. Statistical significance ( $p$-values) was evaluated from the lmerTest package ${ }^{78}$, which uses Satterthwaite approximations of degrees of freedom (further details, including model structures and outputs, can be found in the electronic supplementary material). In addition, chi-squared tests (two-sided) were performed to see whether choices (i.e. probability for success) from each treatment were or were not different from an equal expectation of an individual sea hare to enter either choice chamber of the T-maze (cf. Supplementary Table S4).

For comparisons of behaviours and metabolic rates between developmentally acclimated and adult acclimated groups, planned comparisons were carried out among each treatment pair using glht in the multcomp package and adjusted $p$-values are presented (cf. Supplementary Table S5).

Statistical significance was accepted at the $p<0.05$ level. All the data are means $\pm S D$.

Received: 29 March 2019; Accepted: 26 February 2020;

Published online: 25 March 2020

\section{References}

1. Collins, M. et al. Long-term climate change: projections, commitments and irreversibility in Climate Change 2013: The Physical Science Basis (eds. Stocker, T. F. et al.), Contribution of Working Group I to the Fifth Assessment Report of the Intergovernmental Panel on Climate Change (Cambridge University Press, Cambridge, UK and New York, NY, USA: Cambridge University Press, 2013).

2. Gattuso, J. P. et al. Contrasting futures for ocean and society from different anthropogenic $\mathrm{CO}_{2}$ emissions scenarios. Science 349, aac4722 (2015)

3. Hoegh-Guldberg, O. et al. The Ocean in Climate Change 2014: Impacts, Adaptation, and Vulnerability. Part B: Regional Aspects (eds. Barros, V. R. et al.), Contribution of Working Group II to the Fifth Assessment Report of the Intergovernmental Panel on Climate Change, 1655-1731 (Cambridge, UK and New York, NY, USA: Cambridge University Press, 2014).

4. Stella, J. S., Pratchett, M. S., Hutchings, P. A. \& Jones, G. P. Coral-associated invertebrates: diversity, ecological importance and vulnerability to disturbance. Oceanogr. Mar. Biol. 49, 43-104 (2011).

5. Gazeau, F. et al. The impact of ocean acidification on shelled molluscs, Marine Biology (2013). 
6. Parker, L. M. et al. Predicting the response of molluscs to the impacts of ocean acidification. Biology (invited submission) 2(2), 651-692 (2013).

7. Clements, J. C. \& Hunt, H. L. Marine animal behaviour in a high $\mathrm{CO}_{2}$ ocean. Mar. Ecol. Prog. Ser. 536, 259-279 (2015).

8. Gilman, S. E., Urban, M. C., Tewksbury, J., Gilchrist, G. W. \& Holt, R. D. A framework for community interactions under climate change. Trends Ecol. Evol. 25, 325-331 (2010).

9. Tylianakis, J. M., Didham, R. K., Bascompte, J. \& Wardle, D. A. Global change and species interactions in terrestrial ecosystems. Ecol. Lett. 11, 1351-1363 (2008).

10. Nagelkerken, I. \& Munday, P. L. Animal behaviour shapes the ecological effects of ocean acidification and warming: moving from individual to community-level responses. Global Change Biol. 22, 974-989 (2016).

11. Watson, S.-A. et al. Marine mollusc predator-escape behaviour altered by near-future carbon dioxide levels. Proc. R. Soc. Lond. $B$ Biol. Sci. 281, 20132377 (2014).

12. Watson, S.-A., Fields, J. B. \& Munday, P. L. Ocean acidification alters predator behaviour and reduces predation rate. Biol. Lett. 13, 20160797 (2017).

13. Manríquez, P. H. et al. Ocean acidification affects predator avoidance behaviour but not prey detection in the early ontogeny of a keystone species. Mar. Ecol. Prog. Ser. 502, 157-167 (2014).

14. Wright, J., Parker, L. M., O’Connor, W. A., Ross, P. M. Ocean acidification affects both the predator and prey to alter the predatorprey interactions between the oyster Crassostrea gigas (Thunberg, 1793) and the whelk Tenguella marginalba (Blainville, 1832). Marine Biology 165 (3) (2018).

15. Wright, J. M. et al. The impact of ocean acidification on shell strength and predation of populations of the Pacific oyster Crassostrea gigas. Biological Bulletin 226(3): 269-281. ISSN 10623590 (2014).

16. Schalkhausser, B., Bock, C., Portner, H. O. \& Lannig, G. Escape performance of temperate king scallop, Pecten maximus under ocean warming and acidification. Mar. Biol. 161, 2819-2829 (2014).

17. Spady, B. L., Watson, S. A., Chase, T. J. \& Munday, P. L. Projected near-future $\mathrm{CO}_{2}$ levels increase activity and alter defensive behaviours in the tropical squid Idiosepius pygmaeus. Biol. Open 3, 1063-1070 (2014).

18. Spady, B. L., Munday, P. L. \& Watson, S. A. Predatory strategies and behaviours in cephalopods are altered by elevated $\mathrm{CO}_{2}$. Global Change Biol. 24, 2585-2596 (2018).

19. Dodd, L. F., Grabowski, J. H., Piehler, M. F., Westfield, I. \& Ries, J. B. Ocean acidification impairs crab foraging behaviour. Proc. R. Soc. Lond. B Biol. Sci. 282, 20150333 (2015).

20. Rossi, T., Connell, S. D. \& Nagelkerken, I. Silent oceans: ocean acidification impoverishes natural soundscapes by altering sound production of the world's noisiest marine invertebrate. Proc. R. Soc. Lond. B Biol. Sci. 283, 20153046 (2016).

21. Metcalfe, N. B., Van Leeuwen, T. E. \& Killen, S. S. Does individual variation in metabolic phenotype predict fish behaviour and performance? J. Fish Biol. 88, 298-321 (2016).

22. Burton, T., Killen, S. S., Armstrong, J. D. \& Metcalfe, N. B. What causes intraspecific variation in resting metabolic rate and what are its ecological consequences? Proc. R. Soc. Lond. B Biol. Sci. 278, 3465-3473 (2011).

23. Pettersen, A. K., White, C. R. \& Marshall, D. J. Metabolic rate covaries with fitness and the pace of life history in the field. Proc. R. Soc. Lond. B Biol. Sci. 283, 20160323 (2016).

24. Le Moullac, G. et al. Pinctada margaritifera responses to temperature and $\mathrm{pH}$ : Acclimation capabilities and physiological limits. Estuar. Coast. Shelf Sci 182, 261-269 (2016).

25. Talmage, S. C. \& Gobler, C. J. Effects of elevated temperature and carbon dioxide on the growth and survival of larvae and juveniles of three species of Northwest Atlantic bivalves. PLoS One 6, e26941 (2011).

26. Michaelidis, B., Ouzounis, C., Paleras, A. \& Pörtner, H. O. Effects of long-term moderate hypercapni,a on acid-base balance and growth rate in marine mussels Mytilus galloprovincialis. Mar. Ecol. Prog. Ser. 293, 109-118 (2005).

27. Foo, S. A. \& Byrne, M. Acclimatization and adaptive capacity of marine species in a changing ocean. Adv. Mar. Biol. 74, 69-116 (2016).

28. Sunday, J. M. et al. Evolution in an acidifying ocean. Trends Ecol. Evol. 29, 117-125 (2014).

29. Seebacher, F., White, C. R. \& Franklin, C. E. Physiological plasticity increases resilience of ectothermic animals to climate change. Nat. Clim. Chang. 5, 61-66 (2015).

30. Somero, G. N. The physiology of climate change: how potentials for acclimatization and genetic adaptation will determine 'winners' and 'losers'. J. Exp. Biol. 213, 912-920 (2010).

31. Gienapp, P., Teplitsky, C., Alho, J. S., Mills, J. A. \& Merilä, J. Climate change and evolution: disentangling environmental and genetic responses. Mol. Ecol. 17, 167-178 (2008).

32. Angilletta, M. J. Thermal Adaptation: A Theoretical and Empirical Synthesis (Oxford University Press, 2009).

33. Scott, G. R. \& Johnston, I. A. Temperature during embryonic development has persistent effects on thermal acclimation capacity in zebrafish. Proc. Natl. Acad. Sci. USA 109, 14247-14252 (2012).

34. Merilä, J. \& Hendry, A. P. Climate change, adaptation, and phenotypic plasticity: the problem and the evidence. Evol. Appl. 7, 1-14 (2014).

35. Donelson, J. M., Salinas, S., Munday, P. L. \& Shama, L. N. Transgenerational plasticity and climate change experiments: Where do we go from here? Global Change Biol. 24, 13-34 (2018).

36. Byrne, M. Global change ecotoxicology: identification of early life history bottlenecks in marine invertebrates, variable species responses and variable experimental approaches. Mar. Environ. Res. 76, 3-15 (2012).

37. Marshall, D. J. \& Morgan, S. G. Ecological and evolutionary consequences of linked life-history stages in the sea. Curr. Biol. 21, R718-R725 (2011)

38. Ross, P. M., Byrne, M. and Parker, L. M. Transgenerational effects on molluscs and echinoderms in a climate changed ocean. ICES Journal of Marine Science: Special edition: Towards a broader perspective on ocean acidification research, https://doi.org/10.1093/ icesims/fsv254 ISSN 10959289 (2016)

39. Somero, G. N. The physiology of global change: linking patterns to mechanisms. Annu. Rev. Mar. Sci. 4, 39-61 (2012).

40. Munday, P. L., Warner, R. R., Monro, K., Pandolfi, J. M. \& Marshall, D. J. Predicting evolutionary responses to climate change in the sea. Ecol. Lett. 16, 1488-1500 (2013).

41. Donelson, J. M., Munday, P. L., McCormick, M. I. \& Nilsson, G. E. Acclimation to predicted ocean warming through developmental plasticity in a tropical reef fish. Global Change Biol. 17, 1712-1719 (2011).

42. Nedelec, S. L. et al. Anthropogenic noise playback impairs embryonic development and increases mortality in a marine invertebrate. Sci. Rep. 4, 5891 (2014).

43. Geange, S. W. \& Stier, A. C. Charismatic microfauna alter cyanobacterial production through a trophic cascade. Coral Reefs 29, 393-397 (2010).

44. Horwitz, R., Jackson, M. D. \& Mills, S. C. The embryonic life history of the tropical sea hare Stylocheilus striatus (Gastropoda: Opisthobranchia) under ambient and elevated ocean temperatures. PeerJ 5, e2956 (2017).

45. Osborne, N. J., Webb, P. M. \& Shaw, G. R. The toxins of Lyngbya majuscula and their human and ecological health effects. Environ. Int. 27, 381-392 (2001).

46. Kuffner, I. B. \& Paul, V. J. Effects of the benthic cyanobacterium Lyngbya majuscula on larval recruitment of the reef corals Acropora surculosa and Pocillopora damicornis. Coral Reefs 23, 455458 (2004). 
47. Thacker, R., Ginsburg, D. \& Paul, V. J. Effects of herbivore exclusion and nutrient enrichment on coral reef macroalgae and cyanobacteria. Coral Reefs 19, 318329 (2001).

48. Domenici, P., Torres, R. \& Manríquez, P. H. Effects of elevated carbon dioxide and temperature on locomotion and the repeatability of lateralization in a keystone marine mollusc. J. Exp. Biol. 220, 667-676 (2017).

49. Briffa, M., de la Haye, K. \& Munday, P. L. High $\mathrm{CO}_{2}$ and marine animal behaviour: potential mechanisms and ecological consequences. Mar. Pollut. Bull. 64, 1519-1528 (2012).

50. Dissanayake, A. \& Ishimatsu, A. Synergistic effects of elevated $\mathrm{CO}_{2}$ and temperature on the metabolic scope and activity in a shallow-water coastal decapod (Metapenaeus joyneri; Crustacea: Penaeidae). ICES J. Mar. Sci. 68, 1147-1154 (2011).

51. Gillooly, J. F., Brown, J. H., West, G. B., Savage, V. M. \& Charnov, E. L. Effects of size and temperature on metabolic rate. Science 293, 2248-2251 (2001).

52. Domenici, P., Allan, B. J., Watson, S.-A., McCormick, M. I. \& Munday, P. L. Shifting from right to left: the combined effect of elevated $\mathrm{CO}_{2}$ and temperature on behavioural lateralization in a coral reef fish. PLoS One $\mathbf{9}$ e e87969 (2014).

53. Moya, A. et al. Near-future $\mathrm{pH}$ conditions severely impact calcification, metabolism and the nervous system in the pteropod Heliconoides inflatus. Global Change Biol. 22, 3888-3900 (2016).

54. Nilsson, G. E. et al. Near future carbon dioxide levels alter fish behaviour by interfering with neurotransmitter function. Nat. Clim. Chang. 2, 201-204 (2012)

55. Bornancin, L., Bonnard, I., Mills, S. C. \& Banaigs, B. Chemical mediation as a structuring element in marine gastropod predatorprey interactions. Nat. Prod. Rep. 34, 644-676 (2017)

56. Porteus, C. S. et al. Near-future $\mathrm{CO}_{2}$ levels impair the olfactory system of marine fish. Nat. Clim. Chang. 8, 737-743 (2018).

57. Roggatz, C. C., Lorch, M., Hardege, J. D. \& Benoit, D. M. Ocean acidification affects marine chemical communication by changing structure and function of peptide signalling molecules. Global Change Biol. 22, 3914-3926 (2016).

58. Lefevre, S., Watson, S.-A., Munday, P. L. \& Nilsson, G. E. Will jumping snails prevail? Influence of near-future $\mathrm{CO}_{2}$, temperature and hypoxia on respiratory performance in the tropical conch Gibberulus gibberulus gibbosus. J. Exp. Biol. 218, 2991-3001 (2015).

59. Johnston, I. A. \& Bennett, A. F. Animals and Temperature: Phenotypic and Evolutionary Adaptation (Cambridge, UK: Cambridge University Press, 1996).

60. Pörtner, H. O. Oxygen- and capacity-limitation of thermal tolerance: a matrix for integrating climate-related stressor effects in marine ecosystems. J. Exp. Biol. 213, 881-893 (2010).

61. Seebacher, F. et al. Plasticity of oxidative metabolism in variable climates: molecular mechanisms. Physiol. Biochem. Zool. 83, 721-732 (2010)

62. Sokolova, I. M. \& Pörtner, H. O. Metabolic plasticity and critical temperatures for aerobic scope in a eurythermal marine invertebrate (Littorina saxatilis, Gastropoda: Littorinidae) from different latitudes. J. Exp. Biol. 206, 195-207 (2003).

63. Beldade, R., Blandin, A., O’Donnell, R. \& Mills, S. C. Cascading fitness effects of anemone bleaching on associated anemonefish hormones and reproduction. Nat. Commun. 8, 716 (2017).

64. Matoo, O. B., Ivanina, A. V., Ullstad, C., Beniash, E. \& Sokolova, I. M. Interactive effects of elevated temperature and $\mathrm{CO}_{2}$ levels on metabolism and oxidative stress in two common marine bivalves (Crassostrea virginica and Mercenaria mercenaria). Comp. Biochem. Physiol. A Mol. Integr. Physiol. 164, 545-553 (2013).

65. Pörtner, H. O. \& Farrell, A. P. Physiology and climate change. Science 322, 690-692 (2008)

66. West-Eberhard, M. J. Developmental Plasticity and Evolution (New York, NY, USA: Oxford University Press, 2003).

67. Dupont, S., Dorey, N., Stumpp, M., Melzner, F. \& Thorndyke, M. Long-term and trans-life-cycle effects of exposure to ocean acidification in the green sea urchin Strongylocentrotus droebachiensis. Mar. Biol. 160, 1835-1843 (2013).

68. Parker, L. M. et al. Adult exposure influences offspring response to ocean acidification in oysters. Global Change Biology 18 (1): 82-92. ISSN 13652486 (2012).

69. Bonnard, I. et al. Total structure and inhibition of tumor cell proliferation of laxaphycins. J. Med. Chem. 50, 1266-1279 (2007).

70. Goldenberg, S. U., Nagelkerken, I., Ferreira, C. M., Ullah, H. \& Connell, S. D. Boosted food web productivity through ocean acidification collapses under warming. Global Change Biol. 23, 4177-4184 (2018).

71. Gaylord, B. et al. Ocean acidification through the lens of ecological theory. Ecology 96, 3-15 (2015).

72. Tuomainen, U. \& Candolin, U. Behavioural responses to humaninduced environmental change. Biol. Rev. 86, 640-657 (2011).

73. Arnold, T., Freundlich, G., Weilnau, T., Verdi, A. \& Tibbetts, I. R. Impacts of groundwater discharge at myora springs (North Stradbroke Island, Australia) on the phenolic metabolism of eelgrass, Zostera muelleri, and grazing by the juvenile rabbitfish, Siganus fuscescens. PLoS ONE 9, e104738 (2014).

74. Poore, A. G. B. et al. Direct and indirect effects of ocean acidification and warming on a marine plant-herbivore interaction. Oecologia 173, 1113-1124 (2013).

75. Clark, T. D., Sandblom, E. \& Jutfelt, F. Aerobic scope measurements of fishes in an era of climate change: respirometry, relevance and recommendations. J. Exp. Biol. 216, 2771-2782 (2013).

76. R Core Development Team. R: A language and environment for statistical computing: R Foundation for Statistical Computing (2017).

77. Bates, D., Maechler, M., Bolker, B. \& Walker, S. Fitting linear mixed-effects models using lme4. J. Stat. Softw. 67, 1-48 (2015).

78. Kuznetsova, A., Brockhoff, P. B. \& Christensen, R. H. B. lmerTest package: tests in linear mixed effects models. J. Stat. Softw. 82, 1-26 (2017).

\section{Acknowledgements}

Financial support was provided by LabEx "CORAIL" (ACCLIMACID to R.H. and S.C.M.), the TOTAL Foundation (ICATEC to S.C.M.), the Ministry for an Ecological and Solidary transition (MTES) and the Foundation for Research on Biodiversity (FRB) under their Ocean Acidification program (ECOSYSTEME to S.C.M.), and Contrat de Projets Etat - Polynésie Française to S.C.M. T.N. was funded by the Danish Council for Independent Research (Individual Postdoctoral Grant and Sapere Aude: DFF-Research Talent Grant; DFF-418100297). S.S.K. was supported by a NERC Advanced Fellowship NE/J019100/1 and a European Research Council Starting Grant 640004. S.-A.W. was funded by an IRCP-SNH-SPDD grant. The authors would like to thank Pascal Ung and Franck Lerouvreur, as well as Yannick Chancerelle, Benoit Espiau, Christine Sidobre, Gilles Siu, Vetea Liao, and Nathalie Tolou. We thank Noa Horwitz for help in the field and laboratory, as well as Dr. Steeve Comeau for providing advice and chemicals. This is a contribution to the STORISK project (ANR-15-CE03-0003-08). The authors declare no conflict of interests.

\section{Author contributions}

R.H., T.N., S.-A.W. and S.C.M. conceived the overall project. R.H. and T.N. conducted the field and laboratory work and analysed data. S.H. managed animal husbandry and general maintenance of experimental systems. J.C.A.P. carried out carbonate chemistry analyses. R.H., T.N., S.-A.W, J.C.A.P., R.B., S.H., J.-P.G., R.R.-M., J.V.-D., S.S.K. and S.C.M. assisted in writing and editing the paper. 


\section{Competing interests}

The authors declare no competing interests.

\section{Additional information}

Supplementary information is available for this paper at https://doi.org/10.1038/s41598-020-62304-4.

Correspondence and requests for materials should be addressed to R.H.

Reprints and permissions information is available at www.nature.com/reprints.

Publisher's note Springer Nature remains neutral with regard to jurisdictional claims in published maps and institutional affiliations.

(c) (i) Open Access This article is licensed under a Creative Commons Attribution 4.0 International License, which permits use, sharing, adaptation, distribution and reproduction in any medium or format, as long as you give appropriate credit to the original author(s) and the source, provide a link to the Creative Commons license, and indicate if changes were made. The images or other third party material in this article are included in the article's Creative Commons license, unless indicated otherwise in a credit line to the material. If material is not included in the article's Creative Commons license and your intended use is not permitted by statutory regulation or exceeds the permitted use, you will need to obtain permission directly from the copyright holder. To view a copy of this license, visit http://creativecommons.org/licenses/by/4.0/.

(C) The Author(s) 2020 